\title{
Figurações do insólito, entre texto e tela: curta Murilo
}

\author{
Maria Zilda Cunha' \\ Universidade de São Paulo
}

\section{Resumo}

Este ensaio focaliza O Ex-mágico, curta-metragem dirigido por Olímpio Costa, adaptação fílmica que propõe uma parceria inusitada entre dois contos de Murilo Rubião: O ex-mágico da Taberna Minhota e Teleco o coelhinho, reverberando em insólitas figurações o viés ilógico das narrativas murilianas e as vicissitudes que personagens vivenciam em face da impossibilidade de se esquivar dos exaustivos entraves que os afetam.

\section{Palavras-chave}

Narrativa; Murilo Rubião; Cinema de animação; Olímpio Costa

Usando a ambiguidade como meio ficcional, procuro fragmentar as minhas histórias ao máximo, para dar ao leitor a certeza de que elas prosseguirão indefinidamente, numa indestrutível repetição cíclica.

\section{Introdução}

Murilo Rubião

Murilo Eugênio Rubião (1916-1991), natural de Silvestre Ferraz, hoje Carmo de Minas, aventurou-se na escrita de poemas, romances, novelas e artigos diversos, mas firmou-se no gênero fantástico. Segundo o próprio autor, essa fonte de inspiração advém da leitura dos contos de fada, da Bíblia Sagrada, de obras como

1 Maria Zilda da Cunha - Professora doutora na Universidade de São Paulo; Pós-doutora em Estudos Portugueses e Lusófonos no Instituto de Letras e Ciências Humanas da Universidade do Minho, Portugal (2018) e Pós-Doutora em Ciências, Educação e Humanidades pela UER (2016); Doutora em Letras (USP); Mestre em Comunicação e Semiótica (PUC/SP). Coordenadora da área de Literatura Infantil e Juvenil FFLCH/USP. Líder do grupo de Pesquisa: Produções Literárias e Culturais para Crianças e Jovens FFLCH/USP. Pesquisadora CNPQ.

Revista Ícone (ISSN 2175-215X) • DOI: 10.34176/icone.v17i3.242263

Recife, Vol. 17, N. 3, 335-347, ๑ 2019 PPGCOM/UFPE.

Artigo recebido em 5 jan. 2019 e aprovado em 12 ago. 2019.

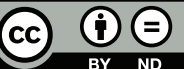


Dom Quixote e As Mil e Uma Noites, da mitologia, além de autores como Machado de Assis e Edgar Allan Poe. Na tessitura desse universo ficcional da tradição, Murilo engendra uma obra excepcional. Parte considerável da crítica confiada ao escritor foi sensível ao processo obsessivo de sua reescrita, bem como ao seu apreço pelo universo do fantástico e à aproximação de seu estilo com o estranho, com o absurdo.

À luz do onírico, do fascínio pela constelação do insólito, o contista mineiro apresenta uma obra de singular riqueza e que consta de apenas 33 narrativas. Sua contística é caracterizada pela economia, por uma sintaxe límpida, por uma redação arquitetada com apuro gramatical e refinada legibilidade. A ficção muriliana constrói, pelo procedimento da ambiguidade e do processo de transformações e metamorfose, uma morada inquietante, abrigando questões identitátias, a ambivalência e as complexidades do viver humano.

Sua arte acomoda elementos do fantástico e, por insólitas vias, abre fendas no imaginário, deixando entrever, na camada do que chamamos realidade, exatamente, um diferente de nós, facultando-nos adentar o império da alteridade. $\mathrm{Na}$ esteira de Ceserani (2006, p. 68), diríamos que suas estratégias não são "apenas representativas, mas cognitivas”. Acessar sua obra demanda atentar não só para a manipulação da ficção, mas também para o apelo imaginativo: "o fantástico é comandado por uma dialética de constituição da realidade e da desrealização própria do projeto criador do autor" (BESSIÈRE, 2012, p.306).

Perscrutar a obra muriliana a partir dessa perspectiva motivou a realização de um projeto maior relacionado ao estágio pós-doutoral, nas universidades UERJ e UFMG, intitulado Murilo Rubião: o fantástico e seus arredores (CUNHA, 2016). Neste ensaio, com objetivos mais modestos, enfocaremos O Ex-mágico, curta-metragem dirigido por Olímpio Costa, adaptação fílmica que propõe uma parceria inusitada entre dois contos de Murilo Rubião, O ex-mágico da Taberna Minhota e Teleco o coelhinho, reverberando em insólitas figurações o viés ilógico das narrativas murilianas, as vicissitudes que os personagens vivenciam em face da impossibilidade de se esquivar dos exaustivos entraves que os afetam. 


\section{O Ex-mágico}

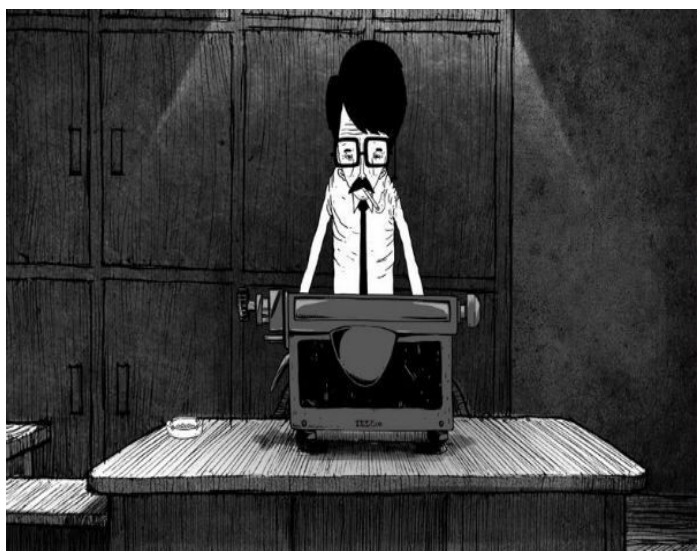

Figura 1: Frame do filme Ex-Mágico

Fonte: Youtube

Em carta $^{2}$ endereçada a Murilo Rubião, datada de 25 de novembro de 1967, Antonio Candido comentava sua leitura, na época recente, do livro Os Dragões, onde reencontrara o conto $O$ ex-mágico da Taberna Minhota. Ao reiterar as elogiosas impressões e comentários já expressos, na ocasião do primeiro contato com a obra, Candido acrescenta o quanto aprecia: "a sua ficção rara, densa, de um insólito despreocupado que suprime qualquer farol e nos faz sentir como se as leis do mundo estivessem normalmente refeitas, uma naturalidade admirável, feita de super-naturalidade"(CANDIDO, 1967). Em 1989, em célebre ensaio A nova narrativa, Candido conferiria a Murilo Rubião o papel de precursor do insólito no cenário das narrativas do século XX, definindo o seu modo de abordar o fantástico como "insólito absurdo".

Inserido no livro de estreia do escritor mineiro em 1947, $O$ ex-mágico da Taberna Minhota pertence a essa fatura do fantástico anunciada por Candido (1989). O conto assinala a irrupção do inesperado, mostrando-se como uma "literatura do contra" (CANDIDO, 2011). Índices ligados à ordem do onírico emergem de seus escritos. Inverossímil e insólito, o relato não oferece visos de verdade, sugerindo - como marca definidora do insólito - a irrupção do inesperado: "tampouco me surpreendi ao retirar do bolso o dono do restaurante"3 (RUBIÃO, 2016, p.15).

Iniciada em média res ( "Hoje sou funcionário público e este não é o meu

2 Carta de Antonio Candido dirigida a Murilo Rubião, encontra-se, entre outras correspondências, no Acervo dos Escritores Mineiros (AEM) da Universidade Federal de Minas Gerais, consulta realizada durante a pesquisa de pós-doutorado realizada em 2016, sob a supervisão do Prof. Dr. Flavio Garcia.

3 Para este trabalho, utiliza-se o livro Murilo Rubião: obra completa. Edição do centenário. Publicado pela Companhia das Letras, em 2016 
desconsolo maior" - RUBIÃO, 2016, p. 15), a história do Ex-mágico é protagonizada por um narrador autodiegético - alguém que fala de si, mas não sabe quem é. $O$ procedimento por ambiguidade, tão caro a Rubião, confere ao personagem duplicidade e indefinição. Notadamente, um conflito de identidade é elemento substancial na intriga, da mesma forma que um sentimento de impotência perpassa todo o enredo, sobretudo pela experiência de um mágico que faz mágicas sem saber como. Além disso, o manipulador de ilusão mostrava-se degradado ao palco dos espetáculos e poderoso para se esquivar dos olhos atentos. "Quando era mágico, pouco lidava com os homens, o palco me distanciava deles" (RUBIÃO, 2016, p 19); como funcionário público, contrariamente, era obrigado ao constante contato com os homens e por isso "necessitava compreendê-los, disfarçar a náusea que me causavam” (RUBIÃO, 2016, p.19).

Empreendendo-se em jornadas desmedidas, e não morrendo, "como esperava" (RUBIÃO, 2016, p. 19), o protagonista narrador vai reconduzindo o incômodo pelo fio narrativo e, por conseguinte, as questões que são suscitadas engendram-se na própria trama. Trata-se de uma construção narrativa que, analogicamente, liga-se à metáfora literária da metamorfose; nota-se como o mágico converte-se na imagem do artista para quem a mágica é compulsiva, e aos olhos de quem o insólito torna-se banal. A banalidade da magia compulsiva é tão absurda quanto o é a do funcionário público petrificada pela burocracia. Duas rotinas banais e absurdas. $\mathrm{O}$ circuito que se fecha no insólito absurdo da narrativa muriliana reverbera na capacidade de perder o que deveria criar: o espanto. Severa é a crítica que se inscreve nesse conto sobre o homem e aquilo que ele próprio funda; a narrativa solidificada sobre um cotidiano comum mira nossa face perplexa e produz aguda denúncia sobre esse "mundo tremendamente tedioso" (RUBIÃO, 2016, p 18), como concluíram os leões. Com efeito, $\mathrm{O}$ ex-mágico da Taberna Minhota, que renegava os seus poderes, que os perde, não consegue refrear um "arrependimento de não ter criado todo um mundo mágico”. (RUBIÃO, 2016, p 21). 
Teleco, o coelhinho

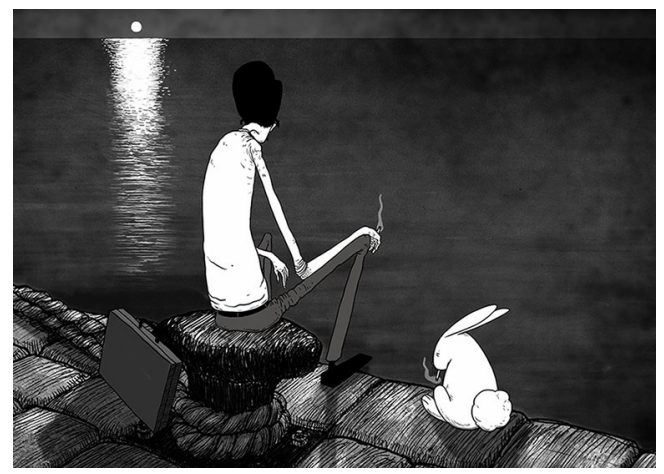

Figura 2 : Frame do filme Ex-Mágico

Fonte: Youtube

Este conto é, assumidamente, o favorito de Murilo Rubião. "Foi no posto 6 que Teleco chegou atrás de mim e pediu um cigarro. Era um domingo, uma beleza de sol. Não triste como este em que eu não veria jamais um coelhinho" 4 . Segundo o próprio autor, é uma história que começa a ser redigida em 1949, no Rio de Janeiro, e concluída, em Madri, em 1958.

“- Moço, me dá um cigarro?” (RUBIÃO, 2016, p. 52). Assim tem inicio a narrativa, cujo encadeamento se faz em singular rítmo, propiciado pelos diálogos em discurso direto e pelo jogo do foco narrativo. $\mathrm{O}$ colecionador de selos, mesmo assumindo seu ponto de vista no relato, deixa entrever a perspectiva do coelho, e cede também voz à Tereza. Além disso, o encadeamento rítmico se faz pelas constantes mutações de Teleco - um coelho que fala e é extremamente versátil em suas trasformações. Teleco remete ao personagem da mitologia grega Proteu, filho de Oceano e de Tetis, incapaz de despertar nos filhos a humanidade, mas capaz de anunciar o porvir e transformar-se em todas as formas que desejasse. As metamorfoses, no conto muriliano, são exuberantes, mas finamente colocadas num vetor de expressiva normalidade.

O narrador participa da diegese, dá cigarro ao coelhinho, afasta-se para deixá-lo ver o mar, comove-se com aquela figura cinzenta e leva o animal para sua própria casa. Tornam-se grandes amigos. Teleco, cuja caraterística é metamorfosear-se, transforma-se em vários bichos. Um dia, dizendo-se um homem chamado Barbosa, traz para casa uma mulher muito bonita, por quem o narrador se apaixona. Tal fato motiva a expulsão do coelhinho. Antônio Barbosa torna-se mágico, fazendo muito sucesso na cidade. Ao voltar, ao ser perguntado, Teleco dá respostas confusas sobre Teresa, transformando-se incontrolavelmente em vários animais.

4 Inserido em um datiloscrito de Rubião de cinco páginas sem título ou data, localizado no Acervo Mutilo Rubião. Consulta realizada em 2016, durante a minha pesquisa de pós-doutoramento 
O colecionador de selos, cansado de vigiar o amigo por vários dias, adormece; ao acordar, percebe que o coelhinho transformara-se "em uma criança loira, encardida, sem dentes. Morta”(RUBIÃO, 2016, p. 61). O narrador dá colo a essa criança sem vida, assiste, assim, a última e patética transformação de Teleco. Ao cessar da magia, sucumbe ele também à morte; analogicamente, narrador e fábula se calam.

\section{O fantástico e as figurações do insólito}

O fantástico, por meio de insólitas figurações, abre fendas no imaginário, e deixa entrever, exatamente, o diferente de nós e da realidade que nos rodeia. Em linhas gerais, o insólito figura-se pela presença de processos cuja marca definidora seja a irrupção do inesperado, do inquietante, podendo ser apreendido como uma manifestação, em termos de elementos da narrativa, de uma incongruência, ou alguma fratura de representação referencial da realidade vivida em nosso real cotidiano.

David Roas fala em "um discurso em constante relação com esse outro discurso que é a realidade, entendida sempre como construção social” (ROAS, 2014, p 8). A compreensão do fantástico, como categoria estética, para o autor catalão, recobre um modo narrativo que emprega o código realista, mas supõe a transgressão deste código. A subversão da realidade é o efeito fundamental do fantástico; e o que vai garantir esse efeito, no plano ficcional, é a manifestação do insólito.

Nessa ordem de ideias, esse "incomum ficcional" traduz-se como uma manifestação inaudita, que prima pela ruptura com a representação coerente da realidade extratextual. É fato que, ao providenciar essa fratura de "representação" da realidade vivida, o caráter estável, que parece ter a realidade, é ameaçado. A ameaça sinaliza "a possibilidade da existência, sob essa realidade estável e delimitada pela razão na qual vivemos, de uma realidade diferente e incompreensível, alheia, portanto, a essa lógica racional que garante nossa segurança e nossa tranquilidade" (ROAS,2014, p.32). É tal o confronto que faz resultar um efeito inquietante e espe-

cular da realidade densa e problemática. Insólita é a realidade ou a ficção?

Como já acenamos em outra ocasião (CUNHA, 2011), narrativas assim configuradas trazem elementos para combater o que poderia resultar em alienação, sugerindo, senão a compreensão da realidade, um questionamento desta e uma investigação em seus interstícios. De acesso interdisciplinar, o fantástico é passível de ser perscrutado em todas as formas artísticas, como pintura, literatura, cinema, $\mathrm{HQ}$, entre outras manifestações. O insólito nasce de repentino estranhamento, não indaga, mas altera o regime normal da consciência, lembrando Cortázar.

\section{Insólitas figurações releem o fantástico muriliano}

Em 2016, cem anos após a morte do escritor de Carmo de Minas, o roteirista e realizador Olímpio Costa traz a lume, em exibição, na USP, um curta metragem de 10 minutos e 41 segundos, cujo roteiro, premiado pela Funarte em 
2010, propõe inusitados diálogos entre os contos O ex-Mágico da taverna Minhota e Teleco, o coelhinho. Essa tradução intersemiótica recebe a animação de Maurício Nunes, cenários de Ricardo Cavani Rosas e é, seguramente, um dos curtas de animação brasileiros mais bem realizados da atualidade. ${ }^{5}$

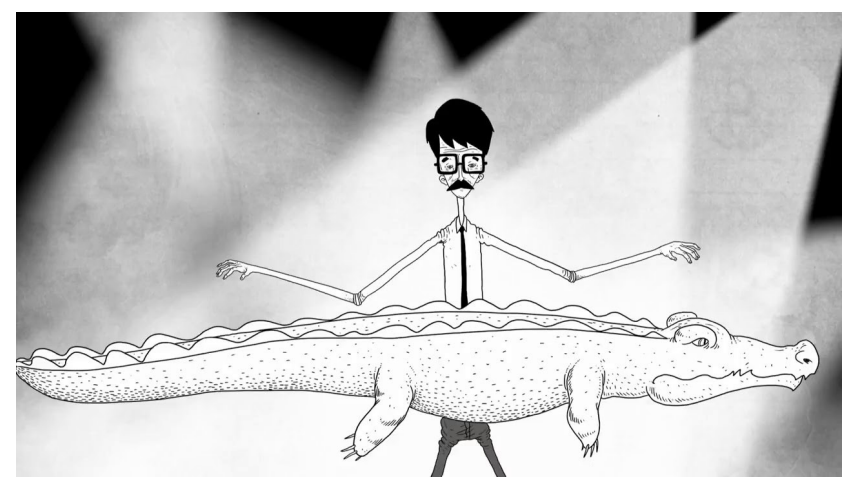

Figura 3: Frame do filme Ex-Mágico Fonte: Youtube

Para o premiado roteirista, "O ex-Mágico da Taberna Minhota, de Rubião, é uma história propícia para o trabalho em modo animação" (COSTA apud REIS, 2016, p.181); ela contém ludicidade, metamorfoses, truques e encantos acontecendo a todo o tempo. Tal conjunto de elementos favorece o que ele denomina de "reinterpretação e diálogo entre os contos Teleco e O Ex-Mágico" (COSTA apud REIS, 2016, p.181).

A primeira parte da animação está sob os efeitos do prelúdio fílmico, composto de intertítulos e sequências de ações. A legenda ("Baseado no conto ' $O$ ex-mágico da Taberna Minhota, de Murilo Rubião”) anuncia a filiação do texto fílmico, bem como o escrito que se segue: ("Inclina, Senhor, o teu ouvido, e ouve-me: porque eu sou desvalido e pobre" Salmos, LXXXV, 1) retoma a citação bíblica que serve de epígrafe ao conto muriliano. Após o prelúdio fílmico, o título do curta-metragem $O$ Ex-mágico surge em letras brancas sobre o fundo preto, em escritura embaçada, de aspecto sinuoso, compondo-se, depois, como fumaça. Iconicamente, perfaz-se um espelhamento sobre a superfície da água.

É sobre a água que, metonimicamente, o protagonista nos é apresentado, pisando sobre uma poça, ao correr para algum lugar que não sabemos qual é. Temos a impressão de que o personagem também não o sabe, percorrendo o cenário inóspito de performance labiríntica, em espaços de ostensiva verticalidade e corre-

5 Importa observar que alguns excertos da análise deste curta estão publicadas, em co-autoria com Maria Auxiliadora Baseio, na revista Letras e Letras/2018. 
dores sombrios. Ele chega a um apartamento e, no acender da luz, são diversos os animais espalhados pelo quarto que compõem o ambiente.

À semelhança do conto muriliano, a narrativa fílmica vai refletindo, ao longo de seu desenrolar, um curioso estado de incertezas. Diferentemente do conto, o ponto de vista no filme não coincide com nenhuma instância intradiegética, o espectador é apresentado ao protagonista, ora por pistas metonímicas, ora em plano frontal, como sentado diante de uma máquina de escrever em cena estática e que se tornará muito recorrente ao longo do curta. A imagem fixa, a utilização de plano médio, que faculta instaurar uma "visão sobre", assim como a voz over, imprimem à narrativa visual capacidade persuasiva, conduzindo o espectador a visualizar e a ouvir o personagem e a condição a que se submete: "Estou cansado. Nasci cansado e entediado".

Os diálogos plásticos, intensos, que se tecem em simulacros, com insólitas misturas entre seres animados e inanimados, ao mesmo tempo que corroboram a fixidez da condição a que o personagem se submete ("cansado e entediado"), contrapõem-se a ela. A plasticidade visual engendra a participação do espectador, confere ludicidade ao enredo, dá força às metamorfoses.

No curta, sela-se uma parceria invulgar entre os personagens, enredos e insólitas situações vividas em $O$ ex-mágico da Taberna Minhota e Teleco, o coelhinho, gerenciando um fantástico que pratica o estranho, em liberdade imaginária, dando vez ao experimentável e ainda indizível.

No revisitar da arte das sombras, a arte das silhuetas animadas, afeita à animação expressionista, vai dando forças à composição de uma ambientação insólita. O curta-metragem inscreve-se, a seu modo, no fantástico, que vai se imprimindo no claro-escuro das imagens, na investida ao mal-estar do espectador em face dos meandros labirínticos com os quais se depara, onde o insólito acontece com normalidade. São os tons escuros e a presença de hachuras que constroem o cenário.

O protagonista se sobressai em razão da claridade que lhe é conferida, ao que se sobrepõem sombras acinzentadas e traços tortuosos utilizados na sua composição corpórea. As criaturas animadas ganham coloração majoritariamente clara, enquanto os objetos inanimados e os cenários acinzentados e povoados de linhas dão um aspecto rígido, imutável. Formas geométricas são escolhidas para a composição: a cidade é feita de quadrados e retângulos; o personagem possui pés quadrados e a armação de seus óculos são dois quadrados. As formas arredondadas são reservadas para os objetos que resultam das magias realizadas, bem como para a jovem (vizinha de mesa) por quem, no conto, ele é apaixonado.

A narrativa não linear e labiríntica perfaz-se pelo movimento do personagem em constante fuga, o seu olhar para trás e a ausência de referências - os seres surgem e não se sabe de onde vêm; há presenças que são anunciadas por índices reconhecíveis pelo espectador, como se houvesse lugares não-acessíveis ou não possíveis de serem vistos. A isso se agrega a alusão às telas de Escher, aos índices ligados à ordem do onírico que emergem, potencializando e selando cumplicidade com o interlocutor, a quem os absurdos incidentes confiam recepção. 
O som e a imagem entram em consórcio nessa produção, criando tensão pela trilha sonora dissonante que se alia ao jogo de luz e de imagens alternadas, como se nota nas cenas do quarto; ao ambientar-se com a cena, o espectador é surpreendido por um movimento de câmera que o conduz a recortes do escritório e de funcionários que aparecem sob a forma de sombras e vozes que se sobrepõem. Um plano geral dá a ver o escritório e seu funcionamento, onde é mínima a movimentação. Une-se ao som a silhueta de um homem carimbando papéis. Com alargamento do campo perceptivo, intelectivamente, depreende-se a metáfora crítica da condição maquínica do homem pós Revolução Industrial, seu hábito repetitivo e automático, a acriticidade de seus gestos, seu aprisionamento à burocracia, a falta de sentido que pode ir além da circunscrição do trabalho e se encaminhar para outras esferas da vida social e pessoal.

Pistas intertextuais potencializam a ludicidade, colidindo com o matiz sombrio da animação. Percebem-se potentes índices do diálogo que se faz no enredo plástico. A marca da máquina de escrever é TELECO. O personagem, ao sair do escritório, aparece em um píer, sentado ao lado de um coelho, ambos estão fumando - apenas a fumaça nos cigarros se move. Explicita-se o entrecruzar das duas narrativas $O$ ex-mágico da Taberna Minhota e Teleco, o coelhinho.

Nosso protagonista, ao voltar à casa, encontra o quarto diferente do visualizado no prelúdio fílmico. O zoom, em um cartaz na parede, remete a Barbosa - grande Mágico "mundialmente famoso". Barbosa seria o funcionário público? $\mathrm{O}$ ex-mágico? O coelho Teleco, que se metamorfoseava?

Em várias tomadas fílmicas são indiciadas as mágicas um dia executadas. $\mathrm{O}$ uso da luz e do movimento, sondando a figura feminina, abre possibilidades a voos imaginativos. Nota-se ao lado do funcionário a existência de uma pasta de papel. O personagem sonda o ambiente para confiar que não está sendo observado. O papel, assim como o cartaz, é notado por meio de um ponto de vista por trás da cabeça do protagonista, como se estivéssemos espionando por cima de seu ombro, ao fim e ao cabo, somos cúmplices. Nosso personagem tosse, e uma pena flutua sobre a folha de papel, caindo sobre ela. Na folha, a pena faz pequenas ondas, e flutua, como se estivesse sobre água. É o início de um processo de diversas metamorfoses - boca, olhos, seios -, como se, naquela pena, estivesse engasgado todo o desejo (desenho) - do que sente por sua vizinha de mesa. Seu dedo toca em um mamilo e a mão começa a derreter até se desfazer completamente. Voltamos a ver, em plano aberto, a mão do personagem levantada, mas completa, o que indica que o momento anterior tratou de uma construção fantasiosa do personagem. Mas a pena ainda está sobre a pasta, nem tudo foi apenas fantasia.

A cena do almoxarifado vazio apresenta analogia com a imagem da rua, com o leão, o mesmo espaço preto em volta de um pequeno retângulo. $\mathrm{O}$ funcionário não entra imediatamente, deixando o espectador na escuridão por alguns

6 No conto Teleco, o coelhinho, de Murilo Rubião (2016, p. 99), lê-se: “Tive mais tarde vagas notícias de um mágico chamado Barbosa a fazer sucesso na cidade". 
segundos. Holofotes vão iluminar o personagem, como se ele estivesse em apresentação em um palco. A trilha sonora acompanha a mudança, assumindo um clima circense. Dos bolsos saem, além de moedas e notas, vários pássaros e uma borboleta; há aplausos e, pela primeira vez, afigura-se o herói um pouco satisfeito. Em sintonia com o conto, o mágico faz surgir entre as mãos um jacaré que se transforma emacordeão, do qual sairá a melodia, que faz a trilha da sequência fílmica, em som intradiegético.

As mágicas e as metamorfoses passam a afetar o corpo do personagem. As mais diversas formas são assumidas por objetos e animais, como visualizamos em outras cenas: coelho, copo de água, quadrados, papéis, mosca. Por fim, perdem a tridimensionalidade e, como pedaços de papel, tornam-se planos e, com uma explosão, fogos de artifício. Voltamos a ver Barbosa/ funcionário público, que dá origem a mais animais: pombas saem de seu pescoço, cobras das calças, dos braços, mais pombas e peixes. Assustado, abre a porta, correndo pela rua, para casa. A cena dessa fuga remete à cena inicial, na qual ele corre olhando para trás, como se estivesse sendo perseguido.

Se, no prelúdio fílmico, ao chegar ao apartamento, os diversos animais estão vivos, espalhados pelo quarto do protagonista, nesta sequência, diferentemente, os animais estão mortos, visualiza-se uma cena sangrenta. $O$ personagem vomita pássaros, que logo saem voando. Essa cena remete à do funcionário tossindo e expelindo uma pena na mesa do escritório.

Num aceno alusivo ao conto, o personagem olha para a própria mão e, no uso de um cutelo, mutila-a. O corte acontece fácil, sem sangue e parece indolor, mas, assim que a mão se desprende do braço, tornam-se cartas de baralho que se espalham pelo chão. Em segundos, formas difusas ocupam o espaço da mão e formam uma nova mão. Uma arma é levada à cabeça, mas transforma-se em um lápis, assim que colocada contra a têmpora. Decepcionado, corre e pula da janela, mas um paraquedas surge em suas costas e abre-se em segundos. Vê-se a silhueta do ex-mágico, cabisbaixo, pousando suavemente. "Eu, que podia criar outros seres, não encontrava meios de me libertar de minha própria existência" (OE M, 2016), diz a voz over. Sentado em uma mesa de bar, em ambiente completamente vazio, acende o cigarro e se metamorfoseia em coelho.

Agora, Barbosa, funcionário, mágico, é, ao mesmo tempo, ele e o coelho que fumava no início. Uma xícara quebrando-se no chão faz a transição para o escritório, vê-se o protagonista diante da máquina de escrever e, por meio de uma voz over, escuta-se: "Não morri conforme esperava. Foram maiores minhas aflições". Seguem-se metamorfoses fora de controle, mas que não impedem a continuidade da escritura. Elas ocorrem independentemente da vontade do nosso protagonista; ele parece acostumado a elas. Enquanto escreve - e nos fala (em voz over) - sobre a falta que sente de fazer mágicas, sua cabeça explode, retomando a forma em segundos, o cenário altera-se - ele está de volta ao bar, datilografando, a voz over chancela de nosso protagonista outro desconforto: "Mas não me conforta a ilusão. Serve apenas para aumentar o arrependimento de não ter criado todo um 
mundo mágico". Ao tirar o papel da máquina de escrever, este transforma-se em uma revoada de pássaros; a máquina, em uma mosca gigante, e uma pilha de papel aparece sobre a mesa, com os óculos quadrados do personagem sobre ela.

A câmera distancia-se e vemos, além da mesa, um picadeiro, com a escrivaninha no centro, alguns papéis ainda no ar, como se um truque de mágica acabasse de ser executado. Não há plateia além do espectador de cinema. A luz se apaga e o espetáculo do ex-mágico chega ao fim. A metáfora da metamorfose da arte cabe perfeitamente a essa obra fílmica; um curta metragem que, no enlace das duas obras literárias, faz figurar a engenhosidade de um universo criado por Murilo Rubião, gerenciando plasticamente fatos insólitos. Constitui, ela própria, espaço de intensa magia e, ao mesmo tempo, indagação sobre questões da realidade social e prosaicas.

\section{Considerações finais}

Um viés comparatista permite divisar críticas à racionalidade formal, à burocratização das instituições e das contradições humanas que livro e tela trazem; os criadores solidarizam-se no julgamento à redução da vida à lógica racional, à razão instrumental, à esterilidade do trabalho burocrático, hiperbolizam a acriticidade dos atos do cotidiano, a falta de identidade, a ausência de projetos de vida - tão habituais na contemporaneidade. Ao acomodar elementos do fantástico, as narrativas literária e fílmica providenciam a fratura de representação da realidade vivida a que já aludimos; uma demanda se faz: a do questionamento da validade dos sistemas de percepção do real. Se a prosa muriliana constrói, pelo procedimento da ambiguidade e do processo de transformação e metamorfose, uma morada inquietante, como já acenamos, plasticamente, a obra fílmica de Olímpio Costa reverencia, em metalinguagem, essa inquietante morada, figurando insolitamente a ambivalência e as complexidades do viver humano.

$O$ fato é que, em ambas as obras, seja na narrativa literária, seja na narrativa fílmica, a indiferença entre prosa e poesia fratura o limite do discurso e abre brechas no imaginário, potencializando uma experiência do possível entre o verbo e a imagem, onde se situam novidades e a potência criativa do insólito do fantástico.

Murilo Rubião, considerado como um dos mais importantes escritores do conto fantástico no Brasil, soube engendrar uma forma tensa e densa de escritura que projeta no texto um insólito movimento. Lembrando Foucault, o que se tece e se destece é a própria "narrativa como acontecimento" (FOUCAULT, 2012, p. 36). O narrador muriliano, por vezes, adentra uma zona de difícil acesso, em que elementos resistem à interpretação e só podem ser tangenciados ou nomeados pela correspondência com imagens (do que ficou por dizer). As narrativas fantásticas de Teleco, o coelhinho e $O$ ex-mágico da Taberna Minhota irrompem do suporte livro, redefinindo-se na linguagem do cinema de animação; engenhosamente revisitadas, no curta dirigido por Olímpio Costa, trazem a lume, em outra expressão 
do imaginário, figurações do insólito capazes de abrir frestas no que chamamos de real e deixar entrever imagens de uma humanidade arrebatadora.

\section{Referências}

BESSIÈRE, Irene. Le récit fantastique. Paris: Larrousse, 1974.

. O Relato Fantástico: forma mista do caso e da adivinha. In: Revista Fronteiraz, São Paulo, n. 9, dezembro de 2012.

CANDIDO, Antonio.. "A nova narrativa". In. A Educação pela Noite e outros ensaios. São Paulo: Ática, 1989. (p. 199- 206)

- A Educação pela noite. Rio de Janeiro: Ouro sobre Azul, 2011.

CESERANI, Remo. O fantástico. Tradução de Nilton Cezar Tridapalli. Curitiba: Ed. UFPR, 2006.

CUNHA, Maria Zilda. "No tecer de novos paradigmas". In: O insólito na Literatura Infantil e Juvenil: Conferências. Rio de Janeiro, Ed.Dialogartes, 2011. (p. 55-71) 2011),

CORTÁZAR, Julio. Valise de cronópio. Trad. Davi Arrigucci Jr. e João Alexandre Barbosa. Org. Haroldo Campos e Davi Arrigucci Jr. São Paulo: Perspectiva, 2004.

O EX-MÁGICO. Direção: Olímpio Costa e Maurício Nunes. Brasil, Cattleya Produções, 2016.

FOUCAULT, Michel. O que é um autor? Lisboa: Ed. Lisboa: Veja, 2012.

REIS, Flávia. “O Ex-mágico: o curta-metragem de Olímpio Costa”. In: Revista Literartes. n. 6. Resenhas. p. $180-188,2016$.

ROAS, David. "A ameaça do fantástico". In: A ameaça do fantástico: aproximações teóricas. Trad. Julián Fuks. São Paulo: Editora Unesp, 2014.

RUBIÃO, Murilo. Obra Completa. Edição do centenário. São Paulo: Companhia das Letras, 2016. 


\section{Unusual figurations, between text and screen: Murilo short film}

\section{Abstract}

This essay focuses on O Ex-mágico, an animated film directed by Olímpio Costa, that is an adaptation of two short stories by Murilo Rubião: O ex-mágico da Taberna Minhota and Teleco, o coelhinho, reverberating in unusual figurations the illogical bias of the Murilo's narratives and the vicissitudes that the characters experience in the face of the impossibility of avoiding the exhaustive obstacles that affect them.

\section{Keywords}

Narrative; Murilo Rubião; Animated cinema; Olimpio Costa.

\section{Sobre o autor}

Maria Zilda Cunha. Doutora em Letras (USP); Mestre em Comunicação e Semiótica (PUC/SP). Coordenadora da área de Literatura Infantil e Juvenil FFLCH/USP. Líder do grupo de Pesquisa Produções Literárias e Culturais para Crianças e Jovens FFLCH/USP. Pesquisadora CNPQ. Pósdoutora em Estudos Portugueses e Lusófonos no Instituto de Letras e Ciências Humanas da Universidade do Minho, Portugal (2018) e Pós-Doutora em Ciências, Educação e Humanidades pela UERJ (2016).

mariazildacunha@hotmail.com 